Andréa Maria Silveira ${ }^{1}$

Elizabeth Costa Dias ${ }^{1}$

Jandira Maciel da Silva ${ }^{1}$

Tarcísio Márcio Magalhães Pinheiro ${ }^{1}$

\section{Compassos e descompassos na trajetória do Serviço Espe- cial de Saúde dos Trabalhadores vinculado ao Hospital das Clínicas da Universidade Federal de Minas Gerais: 30 anos}

\author{
Comings and goings in the 30-year trajectory of the Workers Health \\ Special Service linked to the Minas Gerais \\ Federal University Clinic Hospital
}

${ }^{1}$ Serviço Especial de Saúde dos TrabaIhadores do Hospital das Clínicas da Faculdade de Medicina da Universidade Federal de Minas Gerais. Belo Horizonte, MG, Brasil.

Contato:

Andréa Maria Silveira

E-mail:

silveira@medicina.ufmg.br

Trabalho não subvencionado.

Os autores declaram não haver conflitos de interesse.

\section{Resumo}

Descrição analítica da experiência do Serviço Especial de Saúde dos Trabalhadores da Universidade Federal de Minas Gerais no período de 1983 a 2012. Adotou-se como desenho de investigação a metodologia qualitativa e, por técnica, a leitura reflexiva de documentos, legislação e relatórios do serviço estudado. A trajetória do serviço é periodizada em três momentos enfatizando as principais características do trabalho desenvolvido. Na década de 1980 destaca-se o papel pioneiro da oferta de ações de saúde do trabalhador no estado de Minas Gerais focadas no desvelamento do adoecimento relacionado ao trabalho. Na década de 1990, enfatizam-se as dificuldades de funcionamento devidas ao afastamento de seus profissionais para capacitação e à crise dos hospitais universitários. Na primeira década do novo milênio, o serviço assume as responsabilidades de Centro de Referência Estadual em Saúde dos Trabalhadores e o desafio de compatibilizar a agenda do Sistema Único de Saúde (SUS) com a agenda das instituições federais de ensino superior. A partir de 2011, o serviço redefine sua posição no interior do SUS, buscando o fortalecimento de seu papel de referência para ações de saúde de alta complexidade, formação de recursos humanos e pesquisa. A trajetória do serviço foi influenciada pelos eventos que definiram os contornos da saúde dos trabalhadores e da vida das universidades federais no país.

Palavras-chaves: saúde do trabalhador; serviço de saúde do trabalhador; avaliação; atenção à saúde dos trabalhadores.

\begin{abstract}
This paper is an analytical description of the experience carried out between 1983 and 2012 by the Workers' Health Special Service, linked to the Minas Gerais Federal University, Brazil. For the investigation design, a qualitative methodology was adopted and, as a research tool, a reflexive reading of documents, of the legislation and of the studied service management reports. The service trajectory is divided in three periods: in the eighties, it played a pioneering role by providing workers in the state of Minas Gerais with occupational health care; in the nineties it faced difficulties due to a crisis in university hospitals, and staff shortage as its personnel went through training. In the first decade of the new millennium, the service became a State Workers Health Reference Center, having to cope with the challenge of conciliating both the Brazilian Unified Health System - SUS' and the Federal High Education Institutions agendas. From 2011 the service redefined its function within SUS, seeking to strengthen its role as a reference for highly complex occupational health procedures, human resource training, and research.
\end{abstract}

Keywords: occupational health; occupational health service; evaluation; workers' health care. 


\section{Introdução}

Este texto propõe uma reflexão acerca da trajetória do Serviço Especial de Saúde dos Trabalhadores do Hospital das Clínicas da Universidade Federal de Minas Gerais (SEST/HC/UFMG) considerando as características das práticas de serviço no interior de um hospital universitário. A abordagem entende a trajetória do serviço como um processo social multiforme, contraditório, sujeito a avanços e recuos, em que o novo contém o velho, registrando alguns momentos de ruptura, em que o novo aparece mais forte e incontido (BENJAMIN, 1985).

Entre os condicionantes da organização e do funcionamento do SEST/HC/UFMG, destacam-se variáveis de contexto do cenário mundial e brasileiro da saúde dos trabalhadores e as políticas e as determinações legais que regulam as instituições federais de ensino superior e o Sistema Único de Saúde (SUS), marcadas pela tensão entre as diretrizes do Ministério da Educação e Cultura (MEC) para os hospitais e as instituições federais de ensino superior e o processo de construção da saúde do trabalhador no SUS, em particular na última década.

Assim, o objeto de investigação deste texto encontra-se no campo das relações sociais e institucionais, buscando-se a compreensão dessas relações por meio da análise da trajetória de um serviço de atenção à saúde dos trabalhadores que funciona desde a década de 1980 em uma instituição federal de ensino superior.

\section{Metodologia}

Adotou-se como modelo de investigação a metodologia qualitativa e, por técnica de investigação, a leitura reflexiva da legislação brasileira, dos documentos que tratam das políticas de saúde dos trabalhadores e da política para hospitais universitários, da produção acadêmica e dos relatórios gerenciais do serviço estudado.

A trajetória do serviço é periodizada em três momentos, iniciando por sua criação nos anos 1980, no contexto do processo de organização do movimento da Saúde do Trabalhador e da Reforma Sanitária brasileira. Segue-se a análise de algumas características adotadas nos anos 1990 e início do século XXI, quando o Serviço foi credenciado como Centro de Referência Estadual de Saúde do Trabalhador de Minas Gerais (Cerest/MG), finalizando com a análise da conjuntura atual marcada pelas transformações no modelo de atenção do SUS e dos hospitais universitários vinculados às instituições federais de ensino superior.

\section{A criação do SEST-HC-UFMG na década de 1980}

No cenário sociopolítico dos anos 1980, o país vivia momento de reorganização social ensejado pelo processo de redemocratização e abertura política após os anos mais duros da ditadura militar. São marcas importantes desse período as lutas pelas eleições diretas e pela anistia, a reorganização social e sindical e, no campo da Saúde, o processo da Reforma Sanitária, no bojo do qual emerge o movimento da Saúde do Trabalhador (MENDES; DIAS, 1991; GOMEZ, 2011).

Dias (1994) descreve o processo de construção de ações denominadas de Saúde do Trabalhador na rede pública de saúde em quatro períodos distintos: a) o primeiro, compreendido entre 1978 a 1986, marcado pela difusão das ideias; b) o segundo, entre 1987 a 1990, dedicado à institucionalização; c) o terceiro, de implantação dos serviços na rede pública de serviços, segundo as prescrições da Lei Orgânica da Saúde (n⿳⺈ 8.080) de setembro de 1990 (BRASIL, 1990a) e da Lei $\mathrm{n}^{\circ} 8.142$ de 1990 (BRASIL, 1990b); d) o quarto, das possibilidades que se apresentam, ou o Devir. Nesse cenário, a autora destaca os serviços organizados nos hospitais de ensino, totalizando, em 1992, onze centros que realizam atividades voltadas para a clientela do Sistema Único de Saúde: Universidade de São Paulo, Universidade Estadual de Campinas, Universidade de São Paulo/Ribeirão Preto, Universidade Federal Fluminense, Universidade Estadual do Rio de Janeiro, Universidade Federal de Uberlândia, Universidade Federal do Espírito Santo, Universidade Estadual de Londrina, Universidade Federal de Maringá, Universidade Federal do Rio Grande dos Sul e Universidade Federal de Minas Gerais.

A atenção à saúde dos trabalhadores nos hospitais universitários, devido às suas características e missões institucionais nos anos 1980 e 1990, caracterizava-se pela: prestação de assistência integral e especializada ao trabalhador com ênfase no diagnóstico e no tratamento das doenças relacionadas ao trabalho; capacitação de recursos humanos de nível médio e superior; realização de estudos epidemiológicos e clínicos sobre as doenças relacionadas ao trabalho prevalentes na região; e desenvolvimento de projetos educativos junto a trabalhadores, instituições públicas e outros setores da sociedade no tocante à relação saúde e trabalho (DIAS, 1994).

O papel dos hospitais universitários na atenção à saúde dos trabalhadores ensejou a realização do "Encontro sobre o papel dos Hospitais Universitários na luta pela saúde dos trabalhadores" durante a Reunião da Sociedade Brasileira para o Progresso da Ciência (SBPC), em julho de 1985, em Belo Hori- 
zonte, reunindo 30 profissionais para a reflexão e a divulgação das experiências em curso (DIAS, 1984).

As principais dificuldades então encontradas diziam respeito: à ausência de uma rede hierarquizada de serviços, descaracterizando-os como centros de referência e obrigando-os a fazer atenção primária, secundária e terciária ao mesmo tempo; às deficiências crônicas de recursos humanos, instalações e equipamentos; às limitações técnicas das equipes de trabalho; aos conflitos com os departamentos de Medicina Preventiva decorrentes do componente clínico das atividades realizadas; e à não efetivação da participação dos trabalhadores (DIAS-LAUAR, 1985). Como se verá nas próximas sessões, decorridos 30 anos na trajetória do serviço em foco, parte dessas dificuldades persistem.

O SEST/HC/UFMG (inicialmente denominado Ambulatório de Doenças Profissionais - ADP) foi criado em 1983. O serviço foi pioneiro no estado de Minas Gerais enquanto centro especializado no diagnóstico, no tratamento e na orientação dos trabalhadores acerca das doenças relacionadas ao trabalho, na qualificação profissional e na produção de conhecimento no campo da Saúde do Trabalhador.

O serviço surgiu como fruto de um convênio entre a Fundacentro, o HC/UFMG e o então Instituto Nacional de Previdência Social (INPS). Importante destacar que a Previdência Social, representada pela Coordenação de Acidentes do Trabalho do INPS e pelo Instituto Nacional de Assistência Médica da Previdência Social (Inamps), reconheceu o serviço como centro de apoio para o diagnóstico e o esclarecimento da relação dos problemas de saúde com o trabalho. Essa articulação interinstitucional conferiu aspectos particulares ao processo de constituição do serviço, pois, à época, essa prática era pouco comum na área da saúde (DIAS, 2010).

Deve-se também destacar que, à semelhança de outros serviços que se constituíram neste período no país, a parceria estabelecida, desde a primeira hora, com os trabalhadores organizados em sindicatos mais mobilizados em torno da luta pela saúde teve papel primordial, como bem assinala Lacaz (1996, 2007).

Em Minas Gerais, entre os sindicatos alinhados com ideias do "novo sindicalismo" que incorporaram as questões da vida cotidiana na luta sindical destacam-se o dos Petroleiros, dos trabalhadores de empresas telefônicas (Sintel), dos Metalúrgicos de Belo Horizonte/Contagem e de João Monlevade. A associação academia-movimento sindical, além de pouco comum à época, aconteceu em momento político de restrições da liberdade de associação. ${ }^{2}$ Os trabalhadores, representados por suas lideranças, participaram ativamente das reuniões realizadas às sextas-feiras pela manhã nas instalações do Departamento de Medicina Preventiva e Social (DMPS) da Faculdade de Medicina da UFMG, quando traziam demandas e ajudavam a desenhar a proposta do serviço e as estratégias para sua implementação juntamente com professores, alunos e profissionais das instituições da Saúde, do Trabalho e da Previdência.

Assim, o SEST/HC/UFMG nasceu comprometido com o objetivo de somar esforços na luta dos trabalhadores por melhores condições de vida e saúde e contribuir para desvelar a ocorrência de agravos e doenças relacionados ao trabalho, ainda pouco reconhecidos e registrados no Estado, com destaque para a silicose e as intoxicações por metais pesados, particularmente pelo chumbo.

Em 1985, uma busca ativa de casos de intoxicação por chumbo realizada pelo serviço em pequenas montadoras de baterias automotivas localizadas na região central de Belo Horizonte encontrou um percentual de 70\% dos trabalhadores intoxicados. Esses trabalhadores foram encaminhados para tratamento junto ao serviço e os casos notificados, à Delegacia Regional do Trabalho de Minas Gerais (DRT/MG). O episódio teve grande impacto na mídia local e conferiu visibilidade ao serviço, que passou, a partir de então, a receber enorme demanda espontânea, além de encaminhamentos de trabalhadores por sindicatos, pela DRT/MG e pelo INPS. Esses casos não chegaram a ser publicados, porém foram posteriormente reunidos e estudados por profissionais da DRT/MG (MARINHO-SILVA; FARIA, 1986)

Nesse período, a casuística atendida pelo Serviço começou a se diversificar. Aos trabalhadores intoxicados por chumbo, juntaram-se portadores de perfuração de septo nasal provenientes das empresas de cromagem, de hematopatias associadas à exposição a solventes orgânicos, silicose relacionada à indústria de extração de ouro no subsolo e à indústria de cerâmica sanitária. Em 1984, surgiram os primeiros pacientes apresentando queixas osteomusculares no contexto da então emergente epidemia de Lesões por Esforços Repetitivos (LER).

Desde o início, a equipe do serviço procurou articular o exercício da clínica, de forte expressão em uma escola médica tradicional como a Faculdade de Medicina da UFMG, com práticas da Saúde Coletiva. Porém, este exercício causava surpresa e críticas na Faculdade de Medicina, onde muitos estranhavam a atuação de docentes do Departamento de Medicina Preventiva, envolvidos na construção de um novo

\footnotetext{
${ }^{2}$ Aqueles que viveram e/ou que conhecem a história brasileira, nesse período, sabem avaliar o significado e as dificuldades para a construção desse trabalho conjunto.
} 
modelo de atenção orientado pelo ideário da Saúde Coletiva, na assistência clínica à trabalhadores em um hospital. O SEST foi consolidando sua presença no HC, na UFMG e na sociedade. A criação do Programa de Residência em Medicina Preventiva e Social, com o suporte financeiro da Previdência Social, também no início dos anos 1980, permitiu que os médicos residentes fossem integrados ao serviço.

A efervescente discussão em torno da Reforma Sanitária e do novo sindicalismo constituiu o pano de fundo, no qual muitos residentes do programa vislumbraram possibilidades de uma formação profissional identificada com o interesse dos trabalhadores, alinhada ao movimento de construção do SUS no país e voltada para um mercado de trabalho emergente, que era a assessoria sindical em saúde do trabalhador e os serviços públicos de saúde.

Além da identidade do serviço com o novo momento do país, a residência em Medicina Preventiva e Social com área de concentração em Saúde dos Trabalhadores do HC/UFMG conferia a seus egressos habilidades e competências de ordem prática - por ser uma formação em serviço - sem par entre outras modalidades de formação na área, particularmente entre os cursos de especialização em Medicina do Trabalho eminentemente teóricos, excessivamente focados no cumprimento de exigências legais, divorciados de uma concepção de assistência integral à saúde dos trabalhadores e que apresentavam concepções políticas, éticas e ideológicas distintas.

O cenário de formação consistia na oferta de serviços assistenciais de diagnóstico e tratamento de doenças relacionadas ao trabalho de modo fortemente articulado ao movimento social, na participação em atividades dos grupos de pesquisa sobre o trabalho no âmbito universitário e dos grupos de discussão em torno da reforma sanitária e nos estágios em órgãos do SUS, junto a serviços de saúde do trabalhador de sindicatos de trabalhadores, Serviços de Engenharia de Segurança e Medicina do Trabalho de empresas, Fundacentro, Delegacia Regional do Trabalho dentre outros. Paralelamente, marcou esta época uma efervescente militância dos médicos residentes em torno de partidos e grupos políticos de esquerda, grupos de oposição sindical, associações de médicos residentes etc., o que gerava um ambiente de debate (às vezes de franco conflito) e dinamismo no serviço.

O período foi marcado ainda pela produção de um Manual de Rotinas do Serviço (ASSUNÇÃO, 1992) e várias outras publicações que descreviam a experiência em curso (DIAS-LAUAR et al., 1984; DIAS-LAUAR et al., 1985; DIAS-LAUAR et al., 1989; RIGOTTO et al., 1984; RIGOTTO, 1989) e que se constituíram em referência para outros serviços.

Ainda nesta década, em 1987, foi criado o Núcleo de Saúde do Trabalhador (Nusat) a partir da integração das estruturas dos antigos Inamps e INPS. O Nusat, que contava com uma equipe multiprofissional, composta por médicos clínicos e peritos, assistentes sociais e sociólogos, foi outro fato importante no cenário da saúde dos trabalhadores em Minas Gerais. De seu Conselho Consultivo participavam a UFMG, representada pelo SEST, a Fundacentro, o Ministério do Trabalho e Emprego, a Secretaria Estadual de Saúde, a Secretaria Estadual do Trabalho, o Ministério Público, sindicatos patronais e de trabalhadores. $\mathrm{O}$ conselho se reunia mensalmente e propiciava a discussão dos problemas de saúde do trabalhador do estado e uma articulação interinstitucional que, entre outros avanços, permitiu o arejamento da perícia médica da Previdência Social com impactos para além das fronteiras do estado de Minas Gerais. Contudo, a importância política e institucional do Nusat foi se esvaziando à medida que $o$ SUS assumiu seu papel no campo da saúde dos trabalhadores a partir da Lei $\mathrm{n}^{\circ} 8.080$ (BRASIL, 1990a) e da Lei $\mathrm{n}^{\circ} 8.142$ (BRASIL, 1990b). Além disto, as Leis $\mathrm{n}^{\circ}$ 8.212 e n⿳ํㅡㄹ 8.213 que tratam dos Planos de Benefícios e do Custeio da Previdência Social (BRASIL, 1993), respectivamente, deixaram claras as atribuições da previdência social, as quais excluem ações de diagnóstico, tratamento e reabilitação física, então implementadas pelo Nusat para os trabalhadores vítimas de agravos relacionados ao trabalho. O Núcleo acabou por ser extinto em 1999.

Importante ainda registrar que, seguindo o fluxo de todo esse movimento político em torno da construção de ações de saúde do trabalhador, no que tange a políticas públicas de saúde, ocorreu a estruturação da área de Saúde do Trabalhador no âmbito da Secretaria de Estado da Saúde de Minas Gerais (SES/MG) com a missão de implantar a Política de Saúde do Trabalhador no Estado. Surgem também os Centros de Referência de Saúde do Trabalhador nos municípios de Juiz de Fora e Ipatinga.

\section{A década de 1990 - A expansão das ações de saúde do trabalhador no SUS em Minas Gerais e a redefinição do papel do SEST/HC/UFMG}

A década de 1990 foi marcada, em Minas Gerais, pelo surgimento de outros serviços de saúde do trabalhador, particularmente na região metropolitana de Belo Horizonte (Belo Horizonte, Contagem e Betim), e o fortalecimento do Nusat na primeira metade da década.

No âmbito da SES/MG, a área atravessava dificuldades e desafios, envolvendo debate sobre o modelo de atenção à saúde do trabalhador no SUS e a necessidade de formação de recursos humanos. Neste cenário, a coordenação estadual estabeleceu estreita pareceria com o SEST/HC/UFMG. 
Por ouro lado, a década foi marcada por uma grande crise dos hospitais universitários no Brasil. No HC/UFMG ocorreu demissão de profissionais contratados via fundação de apoio à pesquisa, redução do número de leitos, ameaças de fechamento do hospital, enfim, um ambiente institucional pouco favorável à expansão de ações.

O investimento maciço na qualificação dos quadros docentes no âmbito da UFMG exigiu rearranjos no serviço. Todos os docentes da área saúde e trabalho do DMPS se qualificaram em mestrado ou doutorado naquela década. Também houve cessão de docentes para o Ministério do Trabalho Emprego e saída de profissionais para participação em outros projetos, o que implicou em distanciamentos momentâneos do SEST. Essas mudanças foram responsáveis por desaquecimento das atividades. Cabe aqui esclarecer que o serviço, ao longo de toda a sua trajetória, teve sua operação calcada na atividade assistencial de docentes, médicos residentes e um médico contratado pelo HC, caracterizando-se, desta forma, como um serviço eminentemente médico. Essa composição básica se manteve ao longo do tempo.

A orientação institucional privilegiando a participação de professores em programas de pós-graduação stricto sensu e em atividades de pesquisa fez com que o grupo discutisse a pertinência da manutenção do programa de residência médica e do modelo de participação de docentes em projeto de extensão junto ao HC, atividade subvalorizada nos protocolos institucionais de avaliação de desempenho docente. A despeito deste cenário, optou-se pela manutenção do serviço e da residência, avaliando-se que eram importantes para o fortalecimento de uma política de saúde dos trabalhadores no estado, para a oferta de ações assistenciais em saúde do trabalhador e para a formação de recursos humanos na área para o SUS.

O descenso da Residência de Medicina Preventiva e Social, no final da década de 1980 e início da década de 1990, com redução crescente do número de candidatos ao concurso de seleção, exceto dos interessados na área de saúde do trabalhador, culminou em 1995 com a oferta do programa com apenas esta área de concentração, mostrando a vitalidade e a atração que a saúde do trabalhador exercia sobre os jovens médicos. Mantendo uma tendência que se constituiu na década de 1980, um número importante de egressos foi absorvido por assessorias sindicais em saúde do trabalhador e pelos Programas de Saúde do Trabalhador (PST) surgidos na região metropolitana de Belo Horizonte.

No que diz respeito ao controle social, embora não existisse formalmente constituído um conselho gestor ou conselho de serviço, a participação de lideranças e militantes sindicais era intensa no cenário da saúde do trabalhador no estado de Minas Gerais, particularmente em Belo Horizonte. Destacavam-se metalúrgicos, bancários, eletricitários, trabalhadores em processamento de dados, telefônicos e da indús- tria de plástico. Essas direções sindicais acionavam o serviço com frequência não apenas para encaminhar trabalhadores com suspeita de doenças relacionadas ao trabalho, mas para discutir a agenda sindical de saúde no trabalho do período e solicitar orientação técnica e ajuda na interlocução com outras instituições. Eram numerosos os eventos e as publicações (boletins, jornais etc.) sobre o tema organizados pelas entidades sindicais no período.

A década de 1990 foi marcada também como um período de constituição de assessorias de saúde do trabalhador nos sindicatos maiores. Essas assessorias absorveram profissionais egressos da residência médica do SEST. Entre as categorias que optaram por este caminho, podem ser citadas: Metalúrgicos de Belo Horizonte e Contagem, Metalúrgicos de Betim, Mineiros de Nova Lima, Metabase de Congonhas, Aeroviários, Telefônicos, Eletricitários, Bancários, Metalúrgicos de Ouro Branco, Federação das Indústrias Extrativas, Petroleiros, Sindicatos de Trabalhadores em Saúde, Assistência Social, Previdência e Trabalho, Sindicato dos Trabalhadores Estaduais em Saúde, dentre outros. Isso permitiu a disseminação da "Escola da Saúde do Trabalhador da UFMG”, entendida como um modelo de intervenção nas relações saúde-trabalho por todo o estado.

Essas assessorias operavam com forte ênfase nas ações de vigilância, na negociação de contratos coletivos de trabalho e nas ações de formação de trabalhadores em saúde do trabalhador, além de encaminhar para o SEST os trabalhadores que necessitavam de intervenções diagnósticas e terapêuticas. Ocupavam, ainda, um papel importante amparando direções sindicais para participação em fóruns institucionais que discutiam mudanças na legislação e lutavam pelo aperfeiçoamento e a ampliação da oferta de serviços no interior do SUS, na Previdência Social, no Ministério do Trabalho e Emprego etc. Esses técnicos também ajudavam a manter a relação do movimento sindical com o serviço, em que pese ter sido uma década de enormes dificuldades para a sua sobrevivência (SILVEIRA, 1999, 2002).

\section{A transformação do Serviço em Centro de Referência Estadual de Saúde do Trabalhador de Minas Gerais - Renast}

No final do ano de 2002, a criação da Rede Nacional de Atenção Integral a Saúde dos Trabalhadores (Renast) no âmbito da Secretaria de Assistência à Saúde do Ministério da Saúde, por meio da Portaria $\mathrm{n}^{\circ}$ 1.679, de 19 de setembro de 2002 (BRASIL, 2002), favoreceu uma maior aproximação da Coordenação Estadual de Saúde dos Trabalhadores da SES/MG com o SEST/HC/UFMG com o objetivo de que este 
serviço assumisse o papel de Centro de Referência Estadual em Saúde dos Trabalhadores de Minas Gerais (Cerest/MG), conforme definido na referida portaria.

Esta proposta ganhou aprovação imediata da SES/MG, sendo aprovada pelo Conselho Estadual de Saúde e pela Comissão Intergestores Bipartite, tendo em vista que a portaria enfatizava fortemente ações de natureza assistencial, que não eram mais executadas pelo Estado.

Por outro lado, o grupo do SEST/HC/UFMG considerou que os então 20 anos de implementação de ações de saúde do trabalhador no estado de Minas Gerais, a larga experiência em formação de recursos humanos e o forte compromisso da UFMG com a construção do SUS no estado de Minas Gerais legitimavam e credenciavam o serviço a assumir o papel de Cerest. Além disso, a proposta fortalecia a área de saúde e trabalho na universidade.

Assim, SES/MG e UFMG formalizaram, por meio de convênio firmado em 2003, a incorporação pelo SEST das atribuições do Cerest/MG. Este acordo perdurou até 2011, quando, após o término dos convênios, o SEST retornou à sua condição original de serviço de hospital universitário.

Os sete anos de convênio foram marcados por muitas realizações, mas também por dificuldades. No campo das realizações, devem-se destacar: a liderança no processo de elaboração de três protocolos de atenção diferenciada à saúde dos trabalhadores para o Ministério da Saúde (anamnese ocupacional, intoxicação por chumbo, vigilância das populações expostas a agrotóxicos); a oferta de duas turmas do Curso de Especialização em Saúde do Trabalhador para técnicos do SUS; de curso de aperfeiçoamento em gestão em saúde dos trabalhadores; cursos de atualização em Saúde do Trabalhador para a Atenção Básica; cursos de leitura radiológica padrão Organização Internacional do Trabalho (OIT); cursos de introdução a pneumopatias ocupacionais; atividades de treinamento em serviço para profissionais da rede; organização de congresso internacional sobre exposições a aerodispersoides; curso de atualização em Lesões por Esforços Repetitivos; participação dos técnicos do serviço em atividades de capacitação promovidas por outros Centros de Referência ou pela Coordenação Estadual de Saúde dos Trabalhadores, particularmente capacitações em torno dos agravos relacionados ao trabalho de notificação compulsória e outras capacitações para a atenção básica; produção do livro introdutório sobre saúde do trabalhador para o Curso de Especialização em Saúde da Família e de uma linha guia - Documento de Diretrizes - para apoiar a atuação das referências técnicas em Saúde do Trabalhador; além de financiamento de pesquisas e apoio à realização de inúmeros encontros dos grupos técnicos dos Cerests regionais. Deve-se ainda destacar uma intensa participação em discussões acerca da política para a área junto à Coordenação Estadual em Saúde dos Trabalhadores e à Coordenação Nacional de Saúde dos Trabalhadores do Ministério da Saúde (CENTRO DE REFERÊNCIA ESTADUAL EM SAÚDE DOS TRABALHADORES DE MINAS GERAIS, 2011b).

Entre os desafios enfrentados, destaca-se a dificuldade de atender as exigências da Portaria MS n⿳0 1.679/2002 (BRASIL, 2002) quanto ao quadro mínimo de profissionais do serviço. Em um primeiro momento de funcionamento do Cerest, foram mobilizados profissionais originalmente lotados em outras áreas do Hospital das Clínicas e da SES/MG. Contudo, estes profissionais, por não terem sido, de fato, desonerados de suas atividades originais, não conseguiram se dedicar às atividades do Cerest, comprometendo significativamente seu funcionamento.

As restrições impostas pela própria portaria à contratação de pessoal com recursos da Renast, a exígua disponibilização, pelo Ministério da Educação (MEC), de vagas para os hospitais universitários e fenômeno semelhante no âmbito da Secretaria Estadual de Saúde agravaram o problema, impedindo que o então Cerest/MG concretizasse a vocação multiprofissional e interdisciplinar do modelo da Saúde dos Trabalhadores e ampliasse o leque de ações implementadas e tivesse uma equipe melhor dimensionada à grandeza do trabalho a ser executado.

Além desses fatos de ordem política e legal, o núcleo duro do serviço composto por profissionais do quadro permanente da UFMG (docentes e profissionais médicos) optou pela busca de total integração ao SUS, ou seja, rejeitava-se fortemente o modelo de Centro de Referência enquanto "policlínica” de saúde do trabalhador enclausurada dentro do Hospital Universitário. Ademais, naquele período era quase que impossível a contratação de recursos humanos por meio de concurso público ou nos termos da Consolidação das Leis do Trabalho. Desta forma, buscou-se integração com os serviços de reabilitação física e especialidades médicas já existentes no complexo hospitalar do $\mathrm{HC}$ e na rede SUS, o que reforçou a composição do quadro técnico do serviço fortemente centrada em médicos especialistas em saúde do trabalhador.

A meta era envolver os demais especialistas médicos e profissionais de saúde por meio da sensibilização para o adoecimento originado no trabalho. Essa decisão implicou em custos elevados, expressos no consumo de tempo em incessante atividade de negociação com os parceiros internos ao hospital e à rede, e em dificuldades de natureza ideológica e, muitas vezes, técnica para a implementação de ações 
em sintonia com o modelo da saúde do trabalhador. Supostamente, a constituição de uma equipe própria multiprofissional e de médicos especialistas teria reduzido esse esforço, com atendimento de parte de cuidado dos pacientes internamente ao serviço.

Ressalta-se que a defesa da posição de integração do Hospital Universitário ao Sistema Único de Saúde enfrentou resistências de segmentos da comunidade universitária que viam na regulação pelo gestor municipal uma fonte de interferência do SUS no hospital, até então marcado pelo alto grau de autonomia na definição do perfil assistencial e das linhas de cuidado, muitas vezes orientados mais por interesses de pesquisa e comodidades para os docentes no processo de ensino do que pelas necessidades da população.

O hospital submete-se às exigências da Lei Fede$\mathrm{ral} \mathrm{n} \mathrm{o}^{\mathbf{0}}$ 8.666/1993, que regula licitações e contratos na administração pública (BRASIL, 1993). A aplicação desta lei em um cenário de escassez de técnicos para a execução da atividade meio implicou em enorme desgaste para os gestores do Cerest, em inúmeras dificuldades na realização de processos licitatórios e na efetivação de compras de bens de capital e serviços. Por determinação da Advocacia Geral da União, os recursos destinados pelo Convênio SES/UFMG para as aquisições de bens de capital e material de consumo ficaram no âmbito da universidade, sendo repassados para a Fundação de Desenvolvimento da Pesquisa (Fundep), interveniente do convênio, apenas os gastos com pagamento de pessoal nas modalidades bolsa de extensão, pagamento de autônomo e estagiário, desde que previstos nos planos de trabalho do convênio, o que também não se fez sem conflitos.

O desenvolvimento das ações de Visat também constituiu uma dificuldade, uma vez que os profissionais do SEST/HC/UFMG não eram autoridades sanitárias estaduais. Este fato impedia ou dificultava o acesso aos locais de trabalho, a relação com os municípios, a vigilância das situações de saúde e o acesso aos bancos de dados intra e extrassetoriais no campo da Saúde do Trabalhador. Entretanto, apesar das dificuldades, foram desenvolvidas ações integradas de Visat com outros Cerests, realizadas capacitações e desenvolvidos instrumentos para a Visat.

Outra dificuldade foi a compatibilização da agenda de ensino e pesquisa de uma instituição federal de ensino superior do porte da UFMG com a agenda do SUS de um estado que, como Minas Gerais, possui 853 municípios. Na esfera da universidade, o forte estímulo para o fortalecimento da pós-graduação stricto sensu (mestrado e doutorado) e a valorização dos produtos decorrentes das atividades de pesquisa na avaliação do desempenho individual do docente e do coletivo departamental (publicações de papers em revistas de grande impacto) colocaram os docentes envolvidos nas atividades do Cerest em situação de sobrecarga.

Esses docentes se viram premidos pela necessidade de compatibilizar as exigências de produtividade acadêmica, docência na graduação e pós-graduação e gestão universitária com uma agenda intensa de capacitação (especialização, aperfeiçoamento, atualização) voltada para a rede pública de saúde contando com um grupo reduzido de profissionais.

No que diz respeito às exigências de produtividade científica, ressalta-se que as necessidades urgentes de produção de tecnologias leves, de grande importância para a rede pública de saúde naquele momento (manuais, instruções, protocolos, rotinas etc.) implicam em esforço de pesquisa e elaboração intelectual que dificilmente vão ao encontro das linhas editoriais definidas pelos periódicos científicos, gerando uma produção que, embora de grande utilidade para a rede pública de saúde, é pouco valorizada no meio acadêmico.

Ao mesmo tempo, as demandas crescentes por oferta de capacitações ou participação em capacitações oferecidas por outros Cerests e o nível de gestão da política estadual transformaram-se em ponto de tensão, pois competiam com as demandas internas da universidade.

O programa de residência em Medicina do Trabalho abrigado no Serviço foi organizado a partir do reconhecimento da especialidade, em 2004, pela comissão composta por Associação Médica Brasileira (AMB), Conselho Federal de Medicina (CFM) e Comissão Nacional de Residência Médica (CNRM). O programa é orientado na perspectiva dos valores e da proposta da Saúde do Trabalhador e dá continuidade ao processo de formação de médicos especializados no tema, existente desde a criação do serviço na década de 1980, até então certificada de forma precária. A solicitação de autorização da oferta desta residência à Comissão Nacional de Residência Médica em 2004 amparou-se ainda na expectativa de formar médicos do trabalho alinhados aos processos de trabalho do SUS e preparados para a criação e a consolidação da então nascente Renast no país (DIAS; SILVEIRA, 2004).

Desde então, foram formados 28 profissionais, apenas um dos quais foi absorvido pela Renast. Esta presença discreta dos médicos do trabalho formados pelo serviço nos Cerests, nos níveis centrais de elaboração, implementação e avaliação da política de saúde do trabalhador, resulta da baixa atratividade dos contratos oferecidos para estes profissionais nos níveis municipal e estadual da gestão do SUS em Minas Gerais, com salários pouco competitivos frente 
aos oferecidos pela iniciativa privada, outras agências públicas (Ministério Público, INSS, órgãos do Judiciário etc.) e pelo próprio SUS para o trabalho em outras unidades do sistema (atenção básica e rede de urgência e emergência), pela ausência de carreira e pela preponderância de contratos precários.

Este cenário tem gerado conflitos com as gerações de médicos residentes mais recentes, que percebem o descompasso entre a oferta de um programa de formação em serviço, fortemente modelizado para as necessidades do SUS, a realidade do mercado de trabalho. Assim, ocorrem discordâncias entre docentes/preceptores e médicos residentes. Estes últimos pressionam por uma grade de atividades que privilegie conteúdos teóricos e cenários de aprendizado mais centrados em Serviços de Engenharia de Segurança e Medicina do Trabalho e atividades periciais, nas quais vislumbram um maior e mais bem remunerado mercado de trabalho. Outra ordem de conflitos emerge em torno de posições frente à relação capital/trabalho, da forma de atribuir nexo aos agravos relacionados ao trabalho, do papel de protagonista a ser desempenhado pelo trabalhador na defesa de sua saúde etc., conflitos esses que têm matriz ideológica.

Na atualidade, é importante destacar o perfil delineado ao longo dos últimos 15 anos para os hospitais universitários dentro do SUS, como um novo desafio para o SEST.

No caso do HC/UFMG, o município de Belo Horizonte, desde 1994, responsabiliza-se pela gestão total dos recursos destinados aos serviços de saúde na cidade, implementando controle e avaliação junto a todos os prestadores contratados pelo SUS.

Em 1996, foi celebrado convênio entre a Prefeitura Municipal de Belo Horizonte/Secretaria Municipal de Saúde e o HC/UFMG, criando-se a Unidade de Pronto-Atendimento (PA), que se consolidou como porta de entrada ao HC juntamente com os ambulatórios. Propôs- se ainda o funcionamento ininterrupto desses ambulatórios e das enfermarias do HC de forma desvinculada do calendário de atividades acadêmicas. No período entre 2002 e 2004, vivenciou-se no hospital ampliação das atividades assistenciais com ênfase na média e alta complexidade.

Em 2005, foi firmado convênio global entre o HC/UFMG e o gestor do SUS de Belo Horizonte, em sintonia com as diretrizes estabelecidas pelo Ministério da Saúde e o Ministério da Educação. Esta contratualização previu fluxos de acesso aos serviços ambulatoriais, processos de referência e contrarreferência dos pacientes de Belo Horizonte e outros municípios, inserção do HC no sistema de urgência e emergência da cidade na condição de média e alta complexidade, valorização do progra- ma de humanização, modernização administrativa, controle social e gestão participativa (COSTA; MOTA; FIGUEIREDO, 2009).

Essas mudanças significaram importante avanço na integração do HC ao SUS e em mudanças na oferta de ações assistenciais de saúde do trabalhador implementadas a partir do hospital. A primeira delas diz respeito ao fato de subordinar à Central de Marcação de Consultas (CMC) do município de Belo Horizonte o encaminhamento de casos para o HC, privilegiando munícipes e cidadãos de outros municípios pactuados com Belo Horizonte. Este fato contrariava a missão de referência técnica estadual do Cerest, o que levou à sua não inclusão no referido sistema.

Desta forma, o acesso de trabalhadores aos serviços de assistência do serviço continuou se dando com base em encaminhamentos diretos dos municípios de procedência, particularmente daqueles não cobertos por um Cerest regional. Se por um lado isso favoreceu o acesso à consulta especializada em saúde do trabalhador, por outro aprofundou dificuldades de acesso à propedêutica, aos recursos terapêuticos e às interconsultas de especialidades para trabalhadores não provenientes de Belo Horizonte ou de municípios não pactuados com a cidade. Além disso, mesmo para pacientes residentes em $\mathrm{BH}$, é preciso considerar o fato de que no HC existem especialidades que têm $100 \%$ de suas consultas pactuadas com o município e reguladas pela CMC. Isto significa que o paciente do SEST que necessita de uma dessas especialidades deve retornar à Unidade Básica de Saúde, que o encaminhará via CMC para o especialista, não necessariamente no HC. Obviamente, esta situação é mais dramática para o trabalhador oriundo de outros municípios.

Embora destinado às ações assistenciais de média e alta complexidade não apenas por conta de sua condição de Cerest estadual, mas por estar dentro de um hospital universitário cuja missão definida pelo SUS é a ação assistencial mais complexa, dadas as fragilidades da rede, o Cerest ainda se dedica aos atendimentos que poderiam ser caracterizados como de menor complexidade. Este cenário vem se alterando desde a década passada e, atualmente, os casos de maior complexidade e referenciados pela rede ou por outros serviços respondem por mais de $65 \%$ dos atendimentos realizados (CENTRO DE REFERÊNCIA ESTADUAL EM SAÚDE DOS TRABALHADORES DE MINAS GERAIS, 2011a).

Isso certamente reflete o fortalecimento da Atenção Básica em Saúde na região metropolitana de Belo Horizonte, os resultados das sensibilizações, os processos de capacitação em saúde para o trabalhador na atenção básica e uma mudança de perfil de clientela, particularmente a partir de 2008. 
Uma das características mais marcantes desta mudança de perfil relaciona-se à redução númerica da demanda por serviços assistenciais. Este fato é curioso e contraintuitivo, uma vez que ocorre concomitantemente ao aumento de registro por parte da Previdência Social de casos de doenças relacionadas ao trabalho por meio do Nexo Técnico Epidemiológico - NETP (BRASIL, 2007). Uma hipótese, que exige pesquisa para sua comprovação, é que o NETP eliminou a necessidade de busca de um serviço especializado em saúde do trabalhador no SUS para amparar a luta pelo reconhecimento do nexo de uma doença com o trabalho.

Este fato era corriqueiro no passado, quando os relatórios da equipe técnica do serviço eram amplamente requisitados e nos quais se buscavam não apenas evidências de incapacidade para o trabalho, mas principalmente elementos técnicos para fundamentar a solicitação do nexo do adoecimento com o trabalho e, a partir daí, fortalecer a luta pelo acesso aos benefícios previdenciários específicos. O NETP eliminou em grande escala esta necessidade, sem prejudicar o acesso a serviços propedêuticos e terapêuticos oferecidos pelo SỦS ou o sistema de saúde suplementar nas suas várias especialidades.

Aqui, reitere-se a hegemonia de uma nosologia na qual predominam doenças relacionadas ao trabalho e não doenças ocupacionais sensu stricto, portanto, doenças cuja abordagem curativa individual não foge ao domínio dos especialistas ortopedistas, psiquiatras, dermatologistas, otorrinos, dentre outros, ainda que destes profissionais frequentemente escapem as dimensões coletivas e da determinação pelo processo de trabalho, que exigem intervenções corretivas sanitárias sobre o local de trabalho.

Deve-se considerar, contudo, que, visando escapar ao NETP, grandes empresas implementam novas estratégias de ocultação do adoecimento de seus trabalhadores. Essas estratégias passam principalmente pelo custeio direto de tratamentos e afastamentos do trabalho sem encaminhamento para a previdência social, além de recorrerem sistematicamente dos nexos concedidos via NETP.

Esses trabalhadores, contudo, de uma forma geral, têm procurado o SEST apenas após a demissão, quando esta ocorre. Esta situação sinaliza desconhecimento de direitos trabalhistas e previdenciários, pequena abrangência e impacto das ações de fiscalização implementadas pelo Ministério do Trabalho e pela Vigilância em Saúde do Trabalhador do SUS e fragilidade das entidades sindicais no combate a este tipo de prática.

Outra possibilidade é o fato dos trabalhadores desconhecerem a existência do serviço, particularmente aqueles inseridos no mercado informal de tra- balho. Isso sem contar o desconhecimento por parte dos profissionais de saúde da própria rede, o que reduz as possibilidades de encaminhamento.

No caso do Cerest/MG, ressalta-se ainda a existência de quatro outros estabelecimentos vinculados à Renast, o que evidentemente diluiu a clientela, ainda que este pareça um fator de menor importância, haja vista o crescimento da força de trabalho no mesmo período.

\section{A participação do movimento dos traba- lhadores}

Ao longo da primeira década do novo milênio, vários dos serviços sindicais de saúde do trabalhador foram extintos, adquiriram outros contornos ou perderam a visibilidade. Este processo ocorreu concomitantemente a uma grande migração de militantes sindicais e quadros técnicos empenhados na luta por saúde no trabalho, formados na década anterior, para a ocupação de cargos na administração pública ou para o trabalho em outras áreas.

Nesse cenário, a participação de trabalhadores e suas direções sindicais no cotidiano do serviço foi ficando mais diluída e pontual. Para exemplificar, em 2004 e 2005, quando das discussões para constituição do Conselho de Serviço, participaram usuários, membros do Conselho Estadual de Saúde, a maior parte dos quais vinculados a outros movimentos sociais, como associações de moradores e de portadores de patologias (muitos aposentados e sem inserção no mercado de trabalho), e dirigentes sindicais sem experiência no trato da questão da saúde no trabalho.

Foi elaborada uma proposta de regimento enviada para o Conselho Estadual de Saúde, a qual, contudo, nunca foi apreciada. Desta forma, o Conselho de Serviços não se fez realidade. No âmbito do Hospital das Clínicas, existe um Conselho de Usuários, com participação majoritária de representantes das associações de portadores de doenças e no qual as demandas por ações de saúde do trabalhador são praticamente inexistentes. Essa situação já teria sido identificada em outras instâncias de controle social (LACAZ; FLÓRIO, 2009). Atualmente, participam de forma mais intensa das discussões do serviço os trabalhadores rurais e as cooperativas de trabalhadores em lapidação de quartzo e metalúrgicos. Outras organizações de trabalhadores, embora encaminhem pacientes para atendimento, estabelecem interlocução com o serviço de forma eventual.

As grandes categorias profissionais cujos sindicatos tiveram participação intensa na construção do serviço na década de 1980 passaram por fortes mudanças nos seus processos produtivos e na sua 
vida associativa. A maior parte desses trabalhadores que hoje é contemplada com acesso a serviços de saúde suplementar, parece pouco utilizar de forma rotineira o SUS, incluindo os serviços de referência em saúde dos trabalhadores, exceto em momentos de demissão involuntária e perda de acesso a serviços de saúde suplementar conflito do trabalhador com os profissionais da saúde suplementar, conflitos com a perícia da Previdência Social ou quando de demandas judiciais. Contudo, o serviço permanece uma referência para investigação de casos de adoecimento mais complexos.

Cabe registrar ainda que, embora a luta dos trabalhadores por saúde no trabalho no estado de Minas Gerais tenha recebido diferentes formas de registro histórico, nenhum estudo se debruçou sobre a percepção dos trabalhadores organizados acerca do SEST. Estudo realizado por Marino em 2008, referente à satisfação dos pacientes atendidos no serviço, identificou $90 \%$ de avaliação boa ou muita boa quanto à qualidade do atendimento médico, do atendimento da secretaria, das orientações recebidas, ao tempo de espera, ao tempo de agendamento e às instalações (MARINO, 2008).

\section{Situação atual e perspectivas}

No momento, o SEST/HC/UFMG deve se adequar à situação de inserção em um hospital regulado pelo gestor municipal. Isso diante do fato do serviço continuar funcionando como "porta aberta", atendendo demandas de todo o Estado, o que exige esforço redobrado não apenas para garantir acesso do paciente a todos os procedimentos necessários à boa assistência, mas para conformar condições adequadas de custeio para a pesquisa.

Este processo de adequação deve considerar: os documentos legais que regulamentam os serviços e as ações em saúde do trabalhador no SUS; as demandas dos movimentos sociais; e a entrada no cenário da Empresa Brasileira de Gestão dos Hospitais Universitários (EBSERH), empresa pública dotada de personalidade jurídica de direito privado que foi criada em 2011 pelo Decreto Presidencial no 7.661 (BRASIL, 2011a). O estatuto da empresa determina no seu Artigo $3^{\text {}}$ que a empresa terá por finalidade:

\footnotetext{
a prestação de serviços gratuitos de assistência médico-hospitalar, ambulatorial e de apoio diagnóstico e terapêutico à comunidade, assim como a prestação às instituições públicas federais de ensino ou instituições congêneres de serviços de apoio ao ensino, à pesquisa e à extensão, ao ensino-aprendizagem e à formação de pessoas no campo da saúde pública, observada, nos termos do art. 207 da Constituição a autonomia universitária.
}

A Lei $\mathrm{n}^{\circ}$ 12.550, de 15/12/2011 (BRASIL, 2011b) que autorizou o Poder Executivo a criar a empresa, determina no seu Artigo 2ำ que "a EBSERH terá seu capital social integralmente sob a propriedade da União" e no seu Art. $3^{\circ}$, parágrafo $1^{\circ}$, que:

as atividades de prestação de serviços de assistência à saúde de que trata o caput estarão inseridas integral e exclusivamente no âmbito do Sistema Único de Saúde - SUS.

O parágrafo $2^{\circ}$ determina ainda que:

no desenvolvimento de suas atividades de assistência à saúde, a EBSERH observará as orientações da Política Nacional de Saúde, de responsabilidade do Ministério da Saúde.

Nos termos da prescrição legal, trata-se de empresa estatal, no âmbito do Ministério da Educação que prestará serviços de saúde alinhados à Política Nacional de Saúde. A despeito desses termos, dúvidas quanto à constitucionalidade da empresa vêm sendo levantadas (BRASIL, 2013).

A adesão à empresa foi definida no âmbito interno da UFMG e será seguida de apresentação da proposta de contrato pela empresa e discussão no Conselho Universitário, que poderá aceitar a contratualização ou não. A contratualização supostamente colocará fim aos problemas de custeio de recursos humanos. Atualmente, o hospital possui 738 trabalhadores cooperativados e 1.140 contratados via Fundação de Apoio (HOSPITAL DAS CLÍNICAS, 2013), para os quais a substituição por profissionais concursados nos marcos do Regime Jurídico Único vem sendo reiteradamente recusada pelo Ministério do Planejamento, Orçamento e Gestão, onerando os cofres da instituição, que deve custear esta força de trabalho com recursos provenientes da prestação de serviços ao SUS.

Dada à insuficiência desses recursos, o HC-UFMG, à semelhança de outros hospitais universitários, vê-se constantemente ameaçado de insolvência, o que gera instabilidade institucional e compromete a capacidade de investimento (ANDREAZZI, 2013). Isso dificulta a expansão da prestação de ações de saúde ao trabalhador e a modernização do serviço, uma vez que implica na não contratação ou reposição de pessoal, proibida pelo Acordão 1.520/2006 do Tribunal de Contas da União (BRASIL, 2006), e dificulta medidas modernizadoras como a adoção de prontuário eletrônico, troca de equipamentos, expansão da oferta de serviços etc.

No momento, não está colocada no cenário outra proposta para solucionar a grave crise dos hospitais universitários. Nestes termos, caso ocorra a contratualização, tem-se a expectativa de manutenção da identidade de instituição de ensino e pesquisa em condições organizacionais mais favoráveis para o pla- 
nejamento da expansão da oferta de ações de saúde de uma forma geral. Tal expansão deve ocorrer em uma relação de sintonia com o SUS sem perder de vista a missão de realizar pesquisa e formar recursos humanos.

Foge aos objetivos deste texto a discussão dos marcos regulatórios da Saúde do Trabalhador no SUS. Entretanto, para a reorganização do SEST, é necessário considerar, no mínimo: as prescrições da Política Nacional de Saúde do Trabalhador para o SUS, aprovada pelo Conselho Nacional de Saúde; a Portaria $\mathrm{n}^{\circ}$ 2.728/2009 (BRASIL, 2009a), que reestruturou a Renast; a Portaria n $3.252 / 2009$ (BRASIL, 2009b), que define diretrizes para execução e financiamento das ações de Vigilância em Saúde; e a Portaria $\mathrm{n}^{\mathrm{o}} 4.279 / 2010$, que estabelece diretrizes para a organização da Rede de Atenção à Saúde (RAS) no âmbito do SUS (BRASIL, 2010).

\section{A RAS é definida como:}

arranjos organizativos de ações e serviços de saúde, de diferentes densidades tecnológicas, que integradas por meio de sistemas de apoio técnico, logístico e de gestão, buscam garantir a integralidade do cuidado, por meio da integração sistêmica, de ações e serviços de saúde com provisão de atenção contínua, integral, de qualidade, responsável e humanizada, bem como incrementar o desempenho do Sistema, em termos de acesso, equidade, eficácia clínica e sanitária; e eficiência econômica. (BRASIL, 2010)

A organização da RAS baseia-se na formação de relações horizontais entre os pontos de atenção, tendo a Atenção Primária à Saúde (APS) como centro de comunicação, uma vez que constitui o primeiro nível de atenção, caracterizado pela função resolutiva dos cuidados primários sobre os problemas mais comuns de saúde e o ponto a partir do qual se coordena o cuidado em todos os pontos de atenção.

Na perspectiva da RAS, a Renast pode ser entendida como uma sub-rede temática responsável: pelo cuidado integral à saúde dos trabalhadores, formada pela rede de Cerest; pela inclusão das ações de saúde do trabalhador na atenção básica; pela implementação das ações de promoção e vigilância em saúde do trabalhador; e pela instituição e indicação de serviços de retaguarda, de média e alta complexidade, chamados de Rede de Serviços Sentinela em Saúde do Trabalhador.

A Portaria MS nº 3.252/2009 (BRASIL, 2009b) define que a Visat compõe o Sistema Nacional de Vigilância em Saúde e que, para garantir a integralidade do cuidado, esta deve inserir-se na construção das redes de atenção à saúde.

Portanto, o primeiro grande desafio a ser enfrentado pelo SEST/HC/UFMG é o de redefinir seu papel na Renast e na RAS. Nesta perspectiva, o serviço tem discutido o desenvolvimento das seguintes frentes de trabalho: a) apoio matricial às ações de assistência e vigilância em saúde do trabalhador nos pontos de atenção da rede, em particular na Atenção Primária de Saúde; c) ações de educação permanente para os trabalhadores em geral e, em especial da rede SUS e d) realização de estudos e pesquisas acerca das condições de trabalho e das formas de adoecimento mais frequentes no Estado.

Entende-se por apoio matricial a retaguarda especializada a equipes e profissionais de saúde envolvidos com a atenção à população por meio de suporte técnico-pedagógico em construção compartilhada de diretrizes clínicas e sanitárias entre os componentes de uma equipe de referência e os especialistas (CAMPOS 1999, CAMPOS; DOMITI, 2007, BEZERRA; DIMENSTEIN, 2008).

Para a Saúde do Trabalhador o apoio matricial deve envolver as ações assistências e as de promoção e vigilância da saúde. Na atual configuração da Renast, o SEST pode desempenhar o papel de unidade de saúde matriciadora para todos os pontos de atenção da rede, com ênfase nos Cerests e nas unidades sentinelas. Este matriciamento exige a elaboração de linhas de cuidados para as formas de adoecimentos prevalentes, a adoção de tecnologias de ensino à distância e de telessaúde, entre outras, nas quais o HC/UFMG já possui expertise (ALKMIN, 2010; ANDRADE et al., 2011).

Outro desafio para o serviço, na medida em que ele assume seu papel dentro da Renast, deixando de ser "porta aberta", é aperfeiçoar a sintonia com o movimento organizado de trabalhadores. Neste sentido, a retomada desta parceria histórica cresce em importância, expressa nas demandas que atualmente chegam ao serviço, vindas de trabalhadores dos mais diversos setores produtivos, como, por exemplo, da indústria extrativista vegetal e mineral, metalurgia, assalariados rurais.

O fortalecimento do desenvolvimento de estudos e pesquisas, particularmente aquelas alinhadas às prioridades estratégicas da saúde dos trabalhadores no âmbito do SUS, constitui outra perspectiva inescusável e fundamental à garantia de legitimidade para um serviço de hospital universitário. Ser lócus de realização de pesquisas preferencialmente em parceria com os programas de formação de recursos humanos em nível de pós-graduação é importante para a formação de pesquisadores, pessoal vocacionado para a docência e para a assistência e gestão em saúde do trabalhador. Obviamente, diante do cenário institucional descrito, é importante que se viabilize mecanismos adequados de financiamento junto a órgãos de fomento. 


\section{Considerações Finais}

A experiência do SEST do Hospital das Clínicas da UFMG retrata o esforço de construir a atenção à saúde dos trabalhadores no SUS a partir da inserção em um hospital universitário. Esta trajetória é marcada pelas dificuldades decorrentes da necessidade de operar segundo lógicas por vezes concorrentes (diretrizes e marcos legais para instituições federais de ensino superior $\mathrm{X}$ diretrizes e marcos regulatórios do Sistema Único de Saúde), o que, contudo, não impediu a formação de recursos humanos, a produção de serviços assistenciais e a produção acadêmica em sintonia com as necessidades do SUS.
Em que pesem incertezas quanto à forma de funcionamento e à contratualização pela UFMG da EBESERH, espera-se que o hospital universitário conquiste, no futuro próximo, um modelo de financiamento que traga maior agilidade e estabilidade de custeio, permitindo adequações do corpo clínico e assistencial e planejamento de longo prazo para suas atividades, incluindo as ações de saúde do trabalhador. O fortalecimento do serviço enquanto lócus para a realização de pesquisa, associada à formação de recursos humanos na graduação e na pós-graduação é um desafio cuja conquista consolidará mais ainda o compromisso histórico da UFMG com a construção da saúde dos trabalhadores no Sistema Único de Saúde.

\section{Contribuições de autoria}

Todos os autores deram contribuição substancial no projeto e no delineamento, no levantamento de dados, na elaboração do manuscrito, na sua revisão crítica e na aprovação final da versão a ser publicada.

\section{Referências}

ALKMIM, M. B. M. et al. Teleassistência para municípios remotos do Estado de Minas Gerais: ampliando a atuação geográfica dos Hospitais Universitários. 2010. Disponível em: <http:// melhorespraticas.mec.gov.br/arquivos/ufmg telemarketing.pdf>. Acesso em: 01 mar. 2012.

ANDRADE, M.V. et al. Custo-benefício do serviço de telecardiologia no Estado de Minas Gerais: projeto Minas Telecardio. Arquivos Brasileiros de Cardiologia, São Paulo, v. 97, n. 4, p. 307-316, 2011.

ANDREAZZI, M. F. S. Empresa Brasileira de Serviços Hospitalares: inconsistências à luz da reforma do Estado. Revista Brasileira de Educação Médica, Rio de Janeiro, v. 37, n. 2, p. 275-284, 2013.

ASSUNÇÃO, A. A. (Org.). Manual de rotinas do ambulatório de doenças profissionais. Belo Horizonte: Imprensa Universitária, 1992.

BENJAMIN, W. Obras escolhidas: magia e técnica, arte e política. 4 ed. Rio de Janeiro: Brasiliense, 1985.

BEZERRA, E.; DIMENSTEIN, M. Os CAPS e o trabalho em rede: tecendo o apoio matricial na atenção básica. Psicologia Ciência e Profissão, Brasília, v. 28, n. 3, p. 632-645, 2008.

BRASIL. Decreto nº 6.042, de 12 de fevereiro de 2007. Altera o regulamento da Previdência Social, aprovado pelo Decreto $\mathrm{n}^{\mathrm{o}}$ 3.048, de 6 de maio de 1999, disciplina a aplicação, acompanhamento e avaliação do Fator Acidentário de Prevenção - FAP e do Nexo Técnico Epidemiológico, e dá outras providências. Diário Oficial [da] República Federativa do Brasil, Poder Executivo, Brasília, DF, 12 fev. 2007. Disponível em: <http://www010.dataprev.gov.br/sislex/ paginas/23/2007/6042.htm >. Acesso em: 09 set. 2013.

Decreto $\mathrm{n}^{\circ}$ 7.661, de 28 de dezembro de 2011. Aprova o estatuto social da Empresa Brasileira de Serviços Hospitalares - EBSERH, e dá outras providências. Diário Oficial [da] República Federativa do Brasil, Poder Executivo, Brasília, DF, 29 dez. 2011a. Disponível em: <http://www.planalto.gov.br/ ccivil_03/_Ato2011-2014/2011/Decreto/D7661.htm > . Acesso em: 09 set. 2013.

. Lei $\mathrm{n}^{\circ}$ 8.080, de 19 de setembro de 1990. Dispõe sobre as condições para a promoção, proteção e recuperação da saúde, a organização e o funcionamento dos serviços correspondentes e dá outras providências. Diário Oficial [da] República Federativa do Brasil, Poder Executivo, Brasília, DF, 20 set. 1990a. Disponível em: <http://www.planalto.gov. br/ccivil_03/leis/18080.htm > . Acesso em: 09 set. 2013.

Lei $\mathrm{n}^{\circ}$ 8.142, de 28 de Dezembro de 1990. Dispõe sobre a participação da comunidade na gestão do SUS e sobre as transferências intergovernamentais de recursos financeiros na área de saúde dá outras providências. Diário Oficial [da] República Federativa do Brasil, Poder Executivo, Brasília, DF, 21 dez. 1990b. Disponível em: < http://www.planalto.gov.br/ccivil_03/ leis/18142.htm>. Acesso em: 09 set. 2013.

. Lei $\mathrm{n}^{\circ}$ 8.213, de 24 de julho de 1991. Dispõe sobre os planos de benefícios da Previdência Social e dá outras providências. Diário Oficial [da] República Federativa do Brasil, Poder Executivo, Brasília, DF, 25 set. 1991. Disponível em: http://www.planalto.gov.br/ ccivil_03/Leis/L8213cons.htm. Acesso em: 03 nov. 2009. 
BRASIL. Lei nº 8.666, de 21 de junho de 1993. Regulamenta o art. 37, inciso XXI, da Constituição Federal, institui normas para licitações e contratos da administração pública e dá outras providências. Diário Oficial [da] República Federativa do Brasil, Poder Executivo, Brasília, DF, 24 jun. 1993. Disponível em: <http://www.planalto.gov.br/ccivil_03/leis/l8666cons. htm >. Acesso em: 09 set. 2013.

. Lei $\mathrm{n}^{\circ} 12.550$, de 15 de Dezembro de 2011. Autoriza o Poder Executivo a criar a empresa pública denominada Empresa Brasileira de Serviços Hospitalares - EBSERH; acrescenta dispositivos ao Decreto-Lei $n^{\circ} 2.848$, de 7 de dezembro de 1940 Código Penal; e dá outras providências. Diário Oficial [da] República Federativa do Brasil, Poder Executivo, Brasília, DF, 16 dez. de 2011b. Disponível em: < http:// www.planalto.gov.br/ccivil_03/_Ato2011-2014/2011/ Lei/L12550.htm>. Acesso em: 17 de set. de 2013.

Ministério da Saúde. Portaria n⿳o 1.679, de 19 de setembro de 2002. Dispõe sobre a estruturação da rede nacional de atenção integral à saúde do trabalhador no SUS e dá outras providências. Diário Oficial [da] República Federativa do Brasil, Poder Executivo, Brasília, DF, 20 dez. 2002. Disponível em: <http:/dtr2001.saude.gov.br/sas/PORTARIAS/ Port2002/Gm/GM-1679.htm>. Acesso em: 09 set. 2013.

. Ministério da Saúde. Portaria $\mathrm{n}^{\circ}$ 2.728, de 11 de novembro de 2009. Dispõe sobre a Rede Nacional de Atenção Integral à Saúde do Trabalhador (Renast) e dá outras providências. Diário Oficial [da] da república Federativa do Brasil, Poder Executivo, Brasília, DF, 12 de nov. 2009a. Disponível em: < http://portal.saude. gov.br/portal/arquivos/pdf/portaria_renast_2728.pdf $>$. Acesso em: 09 set. 2013.

. Ministério da Saúde. Portaria MS/GM $\overline{\mathrm{n}^{\circ} \mathrm{3}}$ 3.252 , de 22 de dezembro de 2009. Aprova as diretrizes para execução e financiamento das ações de vigilância em saúde pela União, Estados, Distrito Federal e Municípios. Diário Oficial [da] da república Federativa do Brasil, Poder Executivo, Brasília, DF, 23 dez. 2009b, Brasília, DF. Disponível em: <http:// www.brasilsus.com.br/legislacoes/gm/102068-3252>. Acesso em: 09 set. 2013.

. Ministério da Saúde. Portaria $\mathrm{n}^{\circ} 4.279$, de 30 de dezembro de 2010. Estabelece diretrizes para a organização da Rede de Atenção à Saúde no âmbito do Sistema Único de Saúde (SUS). Diário Oficial [da] República Federativa do Brasil, Poder Executivo, Brasília, DF, 31 dez. 2010. Disponível em: < http:// portal.saude.gov.br/portal/arquivos/pdf/portaria4279_ docredes.pdf>. Acesso em: 09 set. 2013.

. Supremo Tribunal Federal (STF).

Questionada lei sobre empresa pública de serviços hospitalares. Notícias STF, Brasília, DF, 7 jan. 2013. Disponível em: <http://www.stf.jus.br/portal/cms/ verNoticiaDetalhe.asp?idConteudo $=227949>$. Acesso em: 30 set. 2013.
- Tribunal de Contas da União. Acórdão 1520/2006 - Plenário. Relator Marcos Vinicius Vilaça. Julgamento em 23 ago. 2006. Diário Oficial [da] da República Federativa do Brasil, Poder Executivo, Brasília, DF, 30 ago. 2006. Disponível em: < http:// portal2.tcu.gov.br/portal/page/portal/TCU/imprensa/ noticias/noticias_arquivos/016954.pdf $>$. Acesso em: 09 set. 2013.

CAMPOS, G. W. S. Educação Médica, hospitais universitários e o Sistema Único de Saúde. Cadernos de Saúde Pública, Rio de Janeiro, v. 15, n. 1, p. $187-$ 193, 1999.

CAMPOS, G. W. S.; DOMITTI, A. C. Apoio matricial e equipe de referência: uma metodologia para gestão do trabalho interdisciplinar em saúde. Cadernos de Saúde Pública, Rio de Janeiro, v. 23, p. 399-408, 2007.

CENTRO DE REFERÊNCIA ESTADUAL EM SAÚDE DOS TRABALHADORES DE MINAS GERAIS. Relatório de atendimentos 2010. Belo Horizonte, 2011a.

. Relatório de atividades 2006-2010. Belo Horizonte, 2011b.

COSTA, M. C.; MOTA, J. A. C.; FIGUEIREDO, R. C. P. A nova dinâmica institucional do Hospital das Clínicas da UFMG: o projeto de unidades funcionais e a contratualização com o SUS/BH. Revista Médica de Minas Gerais, Belo Horizonte, v. 19, n. 3, p. 269-275, 2009.

DIAS, E. C. 25 anos de criação do ambulatório de doenças profissionais do Hospital das Clínicas da UFMG: celebrando o passado e construindo o futuro. Revista Médica de Minas Gerais, Belo Horizonte, v. 20, p. 3-4, 2010.

. A atenção à saúde dos trabalhadores no setor saúde (SUS), no Brasil: realidade, fantasia ou utopia? 1994. 350 f. Tese (Doutorado em Saúde Pública)Faculdade de Ciências Médicas da Universidade Estadual de Campinas, Campinas, 1994.

- Implantação de um Programa de Saúde Ocupacional no ambulatório do Hospital das Clínicas da UFMG. In: REUNIÃO ANUAL DA SOCIEDADE BRASILEIRA PARA O PROGRESSO DA CIÊNCIASBPC, 36., 1984, São Paulo. Anais... São Paulo: SBPC, 1984. v. 1. p. 72-72.

DIAS, E. C. et al. Atividades Desenvolvidas pela Área de Saúde do Trabalhador do Departamento de Medicina Preventiva da Universidade Federal de Minas Gerais. Cadernos Saúde Coletiva, Rio de Janeiro, v. 1, p. 35-40, 1989.

DIAS-LAUAR, E. C. et al. Implantação do Programa de Saúde Ocupacional no ambulatório do Hospital das Clínicas da UFMG. Revista Brasileira de Saúde Ocupacional, São Paulo, v. 12, n. 48, p. 71-75, 1984. DIAS-LAUAR, E. C. et al. O papel do hospital de ensino na luta pela saúde do trabalhador - uma reflexão sobre o trabalho nos ambulatórios especializados no 
atendimento da doença ocupacional. Belo Horizonte: SBPC, 1985. Relatório Final do Encontro de Serviços Especializados, Sociedade Brasileira para o Progresso da Ciência - SBPC.

DIAS, E. C.; SILVEIRA, A. M. A formação do médico do trabalho: residência médica em foco. Revista Brasileira de Medicina do Trabalho, São Paulo, v. 2, p. 04-10, 2004.

GOMEZ, C. M. Campo da Saúde do Trabalhador: trajetória, configuração e transformações. In: GOMEZ, M. C.; MACHADO, J. M. H.; PENA, P. G. L. Saúde do Trabalhador na Sociedade Brasileira Contemporânea. Rio de Janeiro: Fiocruz, 2011. p. 23-36.

HOSPITAL DAS CLÍNICAS DA UNIVERSIDADE FEDERAL DE MINAS GERAIS. Plano de Reestruturação do Hospital das Clínicas da Universidade Federal de Minas Gerais. Belo Horizonte: HC/UFMG, 2013.

LACAZ, F. A. C. O campo Saúde do Trabalhador: resgatando conhecimento em práticas sobre as relações trabalho-saúde. Cadernos de Saúde Pública, Rio de Janeiro, v. 23, n. 4, p. 757-766, 2007.

Saúde do trabalhador: um estudo sobre as formações discursivas da academia, dos serviços e do movimento sindical.1996. 456 f. Tese (Doutorado em Saúde Pública)-Faculdade de Ciências Médicas da Universidade Estadual de Campinas, Campinas, 1996.

LACAZ, F. A. C.; FLÓRIO, S. M. R. Controle social, mundo do trabalho e as conferências nacionais de saúde da virada do século XX. Ciência e Saúde Coletiva, Rio de Janeiro, v. 14, n. 6, p. 2123-2134, 2009.
MARINHO-SILVA, A.; FARIA, M. P. Análise de acidentes do trabalho ocorridos durante parte do ano de 1983 na Grande Belo Horizonte. Revista Brasileira de Saúde Ocupacional, São Paulo, v. 14, n. 53, p. 2632, 1986.

MARINO, M. Avaliação da expectativa e satisfação dos pacientes em relação ao atendimento recebido no Centro de Referência Estadual em Saúde dos Trabalhadores de Minas Gerais. 2008. $51 \mathrm{f}$. Monografia (Conclusão de Curso)-Hospital das Clínicas, Universidade Federal de Minas Gerais, Belo Horizonte, 2008.

MENDES, R.; DIAS, E. C. Da medicina do trabalho à saúde do trabalhador. Revista de Saúde Pública, São Paulo, v. 25, n. 5, p. 341-349, 1991.

RIGOTTO, R. M. Rotina para condução de casos de intoxicação por chumbo metálico e seus compostos inorgânicos. Revista Brasileira de Saúde Ocupacional, São Paulo, v. 16, n. 66, p. 14-21, 1989.

RIGOTTO, R. M. et. al. Implantação do Programa de Saúde Ocupacional no Ambulatório do Hospital das Clínicas da UFMG. Revista Brasileira de Saúde Ocupacional, São Paulo, v. 12, n. 48, p. 71-75, 1984.

SILVEIRA, A. M. A participação dos trabalhadores na redução e eliminação da nocividade do trabalho. In: MENDES, R. (Org.). Patologia do trabalho. 2. ed. São Paulo: Atheneu, 2002. v. 2, p. 1817-1833.

. Negociando a lei: saúde nos contratos coletivos de trabalho. Revista Brasileira de Saúde Ocupacional, São Paulo, v. 25, n. 95/96, p. 19-34, 1999. 